03;09

\title{
Свечение металлов при их анодировании в дистиллированной воде
}

\author{
(ㄱ Д.С. Овеченко, А.П. Бойченко \\ Кубанский государственный университет, \\ Краснодар, Россия \\ E-mail: bojchenco@yandex.ru
}

Поступило в Редакцию 4 февраля 2019 г. В окончательной редакции 4 марта 2019 г. Принято к публикации 4 марта 2019 г.

На примере анодируемых металлов $\mathrm{Al}$ и Та при напряжении $1.2 \mathrm{kV}$ показана возможность генерации электролюминесценции в чистой дистиллированной воде, что исключает необходимость учета какихлибо добавок электролитов в исходных растворах и упрощает интерпретацию результатов исследований этого явления. Установлено, что продукты высоковольтного анодирования в дистиллированной воде и сопровождающая этот процесс электролюминесценция имеют сходство с таковыми при низковольтном анодировании в водных растворах электролитов.

DOI: 10.21883/PJTF.2019.10.47753.17723

Электролитическое формирование барьерных слоев на металлических $(M e)$ электродах является в настоящее время одним из приоритетных направлений микрои радиоэлектроники, космического материаловедения, нанотехнологий и фотоники в связи с возможностью создания различных наноструктур и материалов на их основе с заданными физико-химическими $[1,2]$, оптическими $[3,4]$ и другими свойствами. Для генерируемого в этом процессе светового излучения разные авторы использовали различную терминологию: гальванолюминесценция [5,6], электрохемилюминесценция [7], электролюминесценция $[8,9]$ и пр. Очевидно, что различие терминов, интерпретация результатов исследований явления и отсутствие единства в понимании его механизма связаны как с сочетанием разнородных $M е$ под какойто полярностью напряжения, так и с преимущественным использованием водных растворов электролитов неорганической или органической природы (кислоты, щелочи, соли), которые фактически представляют собой смеси растворителя и растворенного вещества. На эту особенность условий анодирования $M е$ указывали авторы [2], проводившие его исследования на примере Al в деионизованной воде при постоянном и импульсном напряжении до $2 \mathrm{kV}$. Хотя упомянутая работа [2] посвящена только анодированию $\mathrm{Al}$, описываемые в ней процессы явно указывают на существование электрогенерированной люминесценции. Как в деионизованной, так и в дистиллированной воде (ДВ) нами выявлены условия генерации светового излучения при анодировании Ti, W, In, Ga, Nb, Al, Ta, а также Si при постоянном напряжении на электродах начиная от $500 \mathrm{~V}$ [10]. Это позволяет исследовать явление без влияния каких-либо добавок электролитов, что упрощает интерпретацию результатов. Настоящая работа посвящена первым результатам исследований высоковольтного анодирования на примере $\mathrm{Al}$ и Та как обнаруживающих наиболее яркое свечение в чистой ДВ, которое пока условно будем называть электролюминесценцией (ЭЛ).

$\mathrm{Ee}$ регистрация осуществлялась с помощью фотоэлектронного умножителя (ФЭУ-79), ориентированного фотокатодом к аноду из исследуемого $M e$, выполненного в виде проволоки диаметром $0.5 \mathrm{~mm}$ чистотой $99.999 \%$ для Al и 99.99\% для Та. Анод располагался в кювете из оптического стекла (диапазон пропускания 320-2500 nm) напротив Рt-катода с чистотой металла 99.999\%, выполненного из проволоки того же диаметра и одинаковой с анодом длины. Расстояние между электродами составляло $12 \mathrm{~mm}$, а площадь их рабочей поверхности определялась по высоте анодированной части проволок $22 \mathrm{~mm}$, соответствующей фиксированному в ходе экспериментов уровню жидкости. Удельная электропроводность $\sigma$ исходной ДВ имела значение $1.7 \cdot 10^{-4} \mathrm{~S} / \mathrm{m}$, что соответствует ГОСТ 6709-72. При фиксированном на электродах внешнем напряжении $1.2 \mathrm{kV}$ в ходе всего времени анодирования $t=1700 \mathrm{~s}$ они омывались ДВ общим объемом $20 \mathrm{ml}$ со скоростью потока $0.33 \mathrm{ml} / \mathrm{s}$. Генерируемому в этом процессе излучению $M e$-анодов сопутствовало выделение пузырьков газа на электродах, что однозначно указывало на электролиз воды. По общепринятым методикам регистрировались изменения во времени величин светимости ЭЛ $(I)$ и плотности тока между электродами $(J)$, а по достижении времени анодирования $1700 \mathrm{~s}$ - конечная температура и электропроводность воды, по которым определялось их изменение $(\Delta T$ и $\Delta \sigma)$ относительно исходных значений (начальная температура для всех вариантов эксперимента составляла $300 \mathrm{~K}$ ). По кинетическим зависимостям $J(t)$ и $I(t)$ оценивались исходная плотность тока между электродами $J_{0}$ и момент зажигания ЭЛ $t_{z}$ со светимостью $I_{z}$ при соответствующем ей токе $J_{z}$. Анализ морфологии продуктов анодирования на поверхности

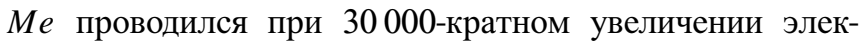
тронного микроскопа. Усредненные по трем измерениям 

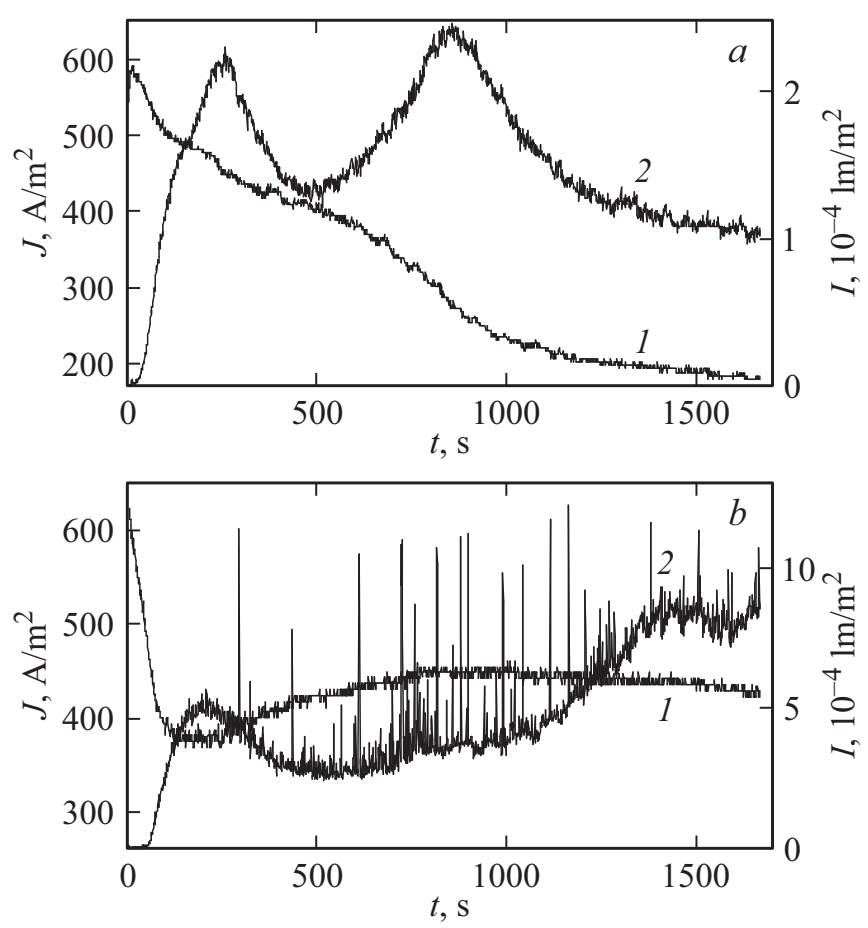

Рис. 1. Кинетические зависимости плотности тока $J(1)$ и светимости ЭЛ $I(2)$ для $\mathrm{Al}(a)$ и Та $(b)$ при их высоковольтном анодировании в ДВ.

результаты оценки перечисленных параметров для $\mathrm{Al}$ и Та представлены на рис. 1,2 и в таблице.

Как видно из рис. 1, при фиксации внешнего напряжения на электродах из разных Ме кинетические зависимости $J(t)$ и $I(t)$ для них количественно различаются. Для системы $\mathrm{Al}-\mathrm{Pt}$ первый параметр характеризуется немонотонным спадом во время всего процесса высоковольтного анодирования, а для системы Тa-Pt ток сначала падает до минимума (порядка $370 \mathrm{~A} / \mathrm{m}^{2}$ ), а затем к $730 \mathrm{~s}$ возрастает до $450 \mathrm{~A} / \mathrm{m}^{2}$, выходя на стационарный уровень. Важно отметить, что в пределах погрешности исходная величина $J_{0}$ в момент приложения напряжения для обеих электродных систем оказывается одинаковой и в среднем составляет $620 \mathrm{~A} / \mathrm{m}^{2}$ (см. таблицу), что указывает на идентичность начальных условий электролиза ДВ и анодирования Ме независимо от их природы. Существенные различия имеют время зажигания ЭЛ и ее кинетика $I(t)$. Так, на Al-аноде вспышка света возникает на 31-й секунде после приложенного напряжения в момент достижения плотности тока $570 \mathrm{~A} / \mathrm{m}^{2}$, а на аноде из Та она появляется через $58 \mathrm{~s}$ при $J_{z}=456 \mathrm{~A} / \mathrm{m}^{2}$ (см. таблицу). Зависимость $I(t)$ для первого $M e$ имеет два максимума. Первый максимум $\left(2.3 \cdot 10^{-4} \mathrm{~lm} / \mathrm{m}^{2}\right)$ соответствует 258-й секунде, а второй $\left(2.5 \cdot 10^{-4} \mathrm{~lm} / \mathrm{m}^{2}\right)-$ 856-й секунде. В случае анода из Та наблюдается более яркая ЭЛ, у которой зависимость $I(t)$ также имеет два максимума со светимостями $5.7 \cdot 10^{-4} \mathrm{~lm} / \mathrm{m}^{2}$ на 208-й секунде и $9.0 \cdot 10^{-4} \mathrm{~lm} / \mathrm{m}^{2}$ на 1410-й секунде, причем в промежутке между максимумами и до окончания процесса анодирования на кинетической кривой $I(t)$ наблюдаются стохастически чередующиеся вспышки амплитудой до $1.2 \cdot 10^{-3} \mathrm{~lm} / \mathrm{m}^{2}$ и длительностью от 1 до $6 \mathrm{~s}$, по виду подобные регистрируемым на начальной стадии высоковольтного пробоя деионизованной воды [11] и для ЭЛ на пропитанных растворами электролитов ионообменных мембранах [12,13]. Учитывая, что вследствие электролиза ДВ на анодах формируется оксидная пленка с высокими диэлектрическими характеристиками, можно говорить об отражении этого процесса для конкретного $M e$ в кинетической зависимости $J(t)$. Так, наблюдаемый за весь период анодирования $\mathrm{Al}$ спад тока в электролитической системе с ним указывает на постепенный рост прочной пленки оксида металла, что со временем затрудняет токоперенос. При изгибе или трении о бумагу анодированной части Al-проволоки оксид не отделяется от нее и не оставляет видимых следов, чего нельзя сказать о Та-аноде. Его оксидная пленка легко поддается разрушению при таких воздействиях. Это позволяет предположить, что в процессе анодирования на поверх-
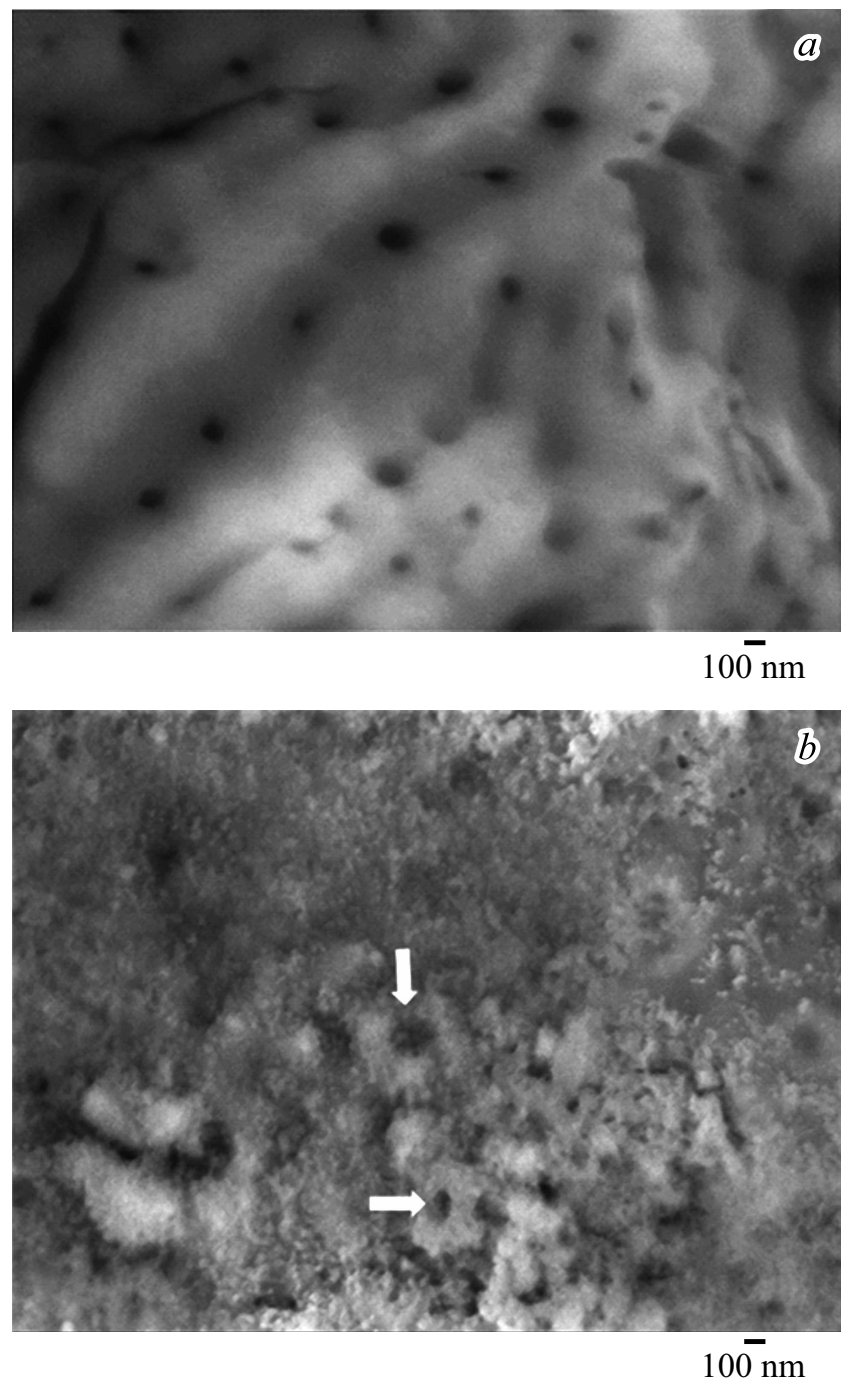

Рис. 2. Электронно-микроскопические изображения $\mathrm{Al}(a)$ и Та $(b)$ после высоковольтного анодирования в ДВ. 
Результаты оценок электрофизических параметров ДВ и характеристик ЭЛ на анодах из $\mathrm{Al}$ и Та

\begin{tabular}{c|c|c|c|c|c|c}
\hline$M e$ & $J_{0}, \mathrm{~A} / \mathrm{m}^{2}$ & $J_{z}, \mathrm{~A} / \mathrm{m}^{2}$ & $t_{z}, \mathrm{~s}$ & $I_{z}, 10^{-6} 1 \mathrm{~m} / \mathrm{m}^{2}$ & $\Delta T, \mathrm{~K}$ & $\Delta \sigma, 10^{-4} \mathrm{~S} / \mathrm{m}$ \\
\hline $\mathrm{Al}$ & $616 \pm 13$ & $570 \pm 20$ & $31 \pm 1$ & $6 \pm 2$ & $11 \pm 1$ & $71 \pm 7$ \\
$\mathrm{Ta}$ & $625 \pm 28$ & $456 \pm 13$ & $58 \pm 1$ & $22 \pm 6$ & $18 \pm 1$ & $9 \pm 1$
\end{tabular}

ности Та создаются условия, препятствующие образованию прочной пленки его оксида. О предполагаемых процессах на поверхности Ме говорят их электронномикроскопические изображения (рис. 2). На Al-аноде видна хорошо известная из литературы упорядоченная структура из несквозных пор диаметром до $130 \mathrm{~nm}$ различной глубины (рис. 2,a), типичная для образующихся при анодировании металла в водных растворах слабых кислот (например, щавелевой или лимонной $[6,8])$. Анод из Та покрывает рыхлая пленка оксида с ажурными элементами ее разрушения, содержащими фрагменты нанопористой структуры (показаны стрелками на рис. $2, b$ ). На положительный тепловой эффект протекания тока в ДВ как высокоомном электролите и электрохимические реакции указывают данные изменения ее температуры и электропроводности, что подтверждает результаты [2], полученные в идентичных условиях. При этом анодирование $\mathrm{Al}$ приводит к большему изменению электропроводности ДВ в отличие от изменения ее температуры, при анодировании Та наблюдается противоположная ситуация. Поскольку в исследуемой системе электродов находится только ДВ, очевидным участником процессов свечения $M e$-анодов могут быть анионы гидроксила. Согласно рассмотренному в [6] механизму их разрядки, для эффективной генерации ЭЛ на аноде должна сформироваться пленка оксида оптимальной для этого толщины, на что требуется определенное время. Судя по данным таблицы, при высоковольтном анодировании $\mathrm{Al}$ и Та в ДВ этому времени соответствует $t_{z}$, которое лежит в пределах минуты. Вопросу оценки оптимальной для возникновения ЭЛ толщины оксида, установлению природы центров свечения, влияния на них различных факторов, включая образующиеся продукты электролиза ДВ (а также бидистиллированной и деионизованной воды), планируется посвятить отдельные публикации. Однако по полученным данным и их большому сходству с имеющимися в литературе для водных растворов электролитов можно уже сейчас говорить не только о возможности анодирования Al и Та (очевидно, и других $M e[14])$ в ДВ как электролите с низкой электропроводностью, но и об интерпретации результатов исследований ЭЛ (особенно ее спектроскопии $[6,8]$ ), свободных от учета каких-либо добавок электролитов в воде. В заключение отметим, что в ряду $M e$-анодов, таких как Pt, Pd, Ir, Rh, Sn, $\mathrm{Cu}, \mathrm{Ag}, \mathrm{Cr}$ и Mo, при напряжении даже $2 \mathrm{kV}$ в ДВ не было обнаружено светового излучения, несмотря на формирование у трех последних металлов заметной пленки продуктов анодирования.

\section{Конфликт интересов}

Авторы заявляют, что у них нет конфликта интересов.

\section{Список литературы}

[1] Hickmott T.W. // J. Appl. Phys. 2009. V. 106. P. 103719 (1-9). DOI: $10.1063 / 1.3262619$

[2] Lisenkov A.D., Poznyak S.K., Zheludkevich M.L., Ferreira G.S. // J. Electrochem. Soc. 2016. V. 163. P. 364-368. DOI: $10.1149 / 2.0881607$ jes

[3] Длугунович В.А., Жумарь А.Ю., Курилкина С.Н., Мухуров Н.И. // ЖПС. 2015. Т. 82. № 5. С. 766-772.

[4] Gu J.-J., Yang S.-M., Dong M.-Y., Qi Y.-K. // J. Alloys Compd. 2017. V. 728. P. 93-99. DOI: 10.1016/j.jallcom.2017.08.272

[5] Гардин Ю.Е., Кулабухов В.М., Легостаев В.А. // Электронная техника. 1972. Сер. 5. Вып. 2(27). С. 83-87.

[6] Stojadinović S., Vasilić R., Kasalica B., Belca I., Zeković L. // Electrodeposition and surface finishing: fundamentals and applications. Ser. Modern Aspects of Electrochemistry. V. 57. N.Y:: Springer-Verlag, 2014. P. 241-302.

DOI: $10.1007 / 978-1-4939-0289-7 \_5$

[7] Ягов В.В. // Докл. РАН. 2010. Т. 432. № 1. С. 63-66.

[8] Гриднев А.Е., Чернышев В.В. // Вестн. ВГУ. Сер. Физика, математика. 2005. № 2. С. 8-10.

[9] Zecović L.J.D., Urošević V.V. // Thin Solid Films. 1981. V. 86. P. 347-350. DOI: 10.1016/0040-6090(81)90342-4

[10] Овеченко Д.С., Бойченко А.П. // VIII Междунар. конф. по фотонике и информационной оптике. Сб. научных трудов. М.: НИЯУ МИФИ, 2019. С. 407-408.

[11] Yang Y., Cho Y.I., Fridman A. // AIP Adv. 2012. V. 2. P. 042153 (1-6). DOI: 10.1063/1.4769080

[12] Бойченко А.П., Прокопенко А.В., Яковенко Н.А. // ЖФХ. 2007. T. 81. № 11. C. 2093-2095.

[13] Савиновских Е.Г., Бойченко А.П., Яковенко Н.А. // Письма в ЖТФ. 2010. Т. 36. В. 20. С. 75-79.

[14] Voon C.H., Lim B.Y., Hashim U., Mohd Khairuddin Md A., Sam S.T., Foo K.L., Ten S.T. // Appl. Mech. Mater. 2015. V. 754-755. P. 1131-1135.

DOI: 10.4028/www.scientific.net/AMM.754-755.1131 